\title{
Evaluation of thermal performance of wire mesh solar air heater
}

\author{
P. Velmurugan and P. Ramesh \\ Department of Mechanical Engineering, Annamalai University, Annamalai Nagar-608002, Chidambaram, TN, India \\ pvsrlme@gmail.com
}

\begin{abstract}
Solar energy is an economical alternative to the today's energy demand. Solar air heater is used for heating the air economically but produces low thermal efficiency. In this study, an attempt has been made to increase the thermal efficiency of solar air heater by using a wire mesh to enhance the heat transfer, thereby increasing the efficiency. The matrix solar air heater with a wire mesh produces higher thermal efficiency over the conventional flat plate solar air heater.
\end{abstract}

Keywords: Solar energy, air heater, wire mesh, thermal efficiency, performance analysis.

Introduction

Solar air heaters have a low efficiency due to low convective heat transfer coefficient between the air and absorber plate which leads to higher temperature of the absorber plate resulting in maximum thermal losses to environment (Prasad \& Mullick, 1983). The flat plate air collectors have low heat transfer coefficient which results in low thermal efficiency. If the area available for heat transfer is not greater than the projected area of the absorber, the absorber becomes necessarily hot, which leads to higher heat losses. Researchers have attempted various modifications in flat solar air heater to enhance the heat transfer rate by incorporating modifications between absorber plate and glass plate such as using an absorber with fins attached (Hachemi, 1995; Yeh \& Lin, 1996), corrugated absorber (Hollands, 1963; Choudhury, 1988), porous materials such as stones (Swartman \& Ogunladeo, 1966), crushed glass (Collier \& Arnold,1980), wool (Sorous \& Hassab, 1986) and metal wool (Lansing et al., 1993).

In this paper an attempt has been made to fabricate a solar air heater with a low carbon steel wire mesh and to determine the performance of modified solar air heater experimentally and compared with conventional flat plate solar heater. The application of solar air heater are drying or curing of agricultural products, space heating for comfort, regeneration of dehumidifying agents, seasoning of timber, curing industrial products such as plastics.

\section{Details of experimental set-up}

The schematic illustration of the experimental set-up is show in Fig.1. The experimental set up is an outdoor flow loop that consists of a wire mesh collector with entrance and exit sections, blower, auto-transformer, vane type anemometer, pyranometer and thermocouple for temperature measurement. The collector plate $1 \mathrm{~mm}$ thick made of low carbon steel sheet of area of $2.4 \mathrm{~m} \times 0.9 \mathrm{~m}$ with an $18^{\circ}$ angle of inclination (Rittidech \& Wannapakne, 2007). The plate was then painted black

.

(Kalogirou, 2004). The $20 \mathrm{~mm}$ wire mesh screen is placed between absorber plate and glass cover- 2 as shown in Fig. 2. The spacing between glass cover-1 and glass cover-2 is $20 \mathrm{~mm}$. The bottom of the collector duct is insulated with glass wool of $20 \mathrm{~mm}$

Fig. 1. Experimental set up.

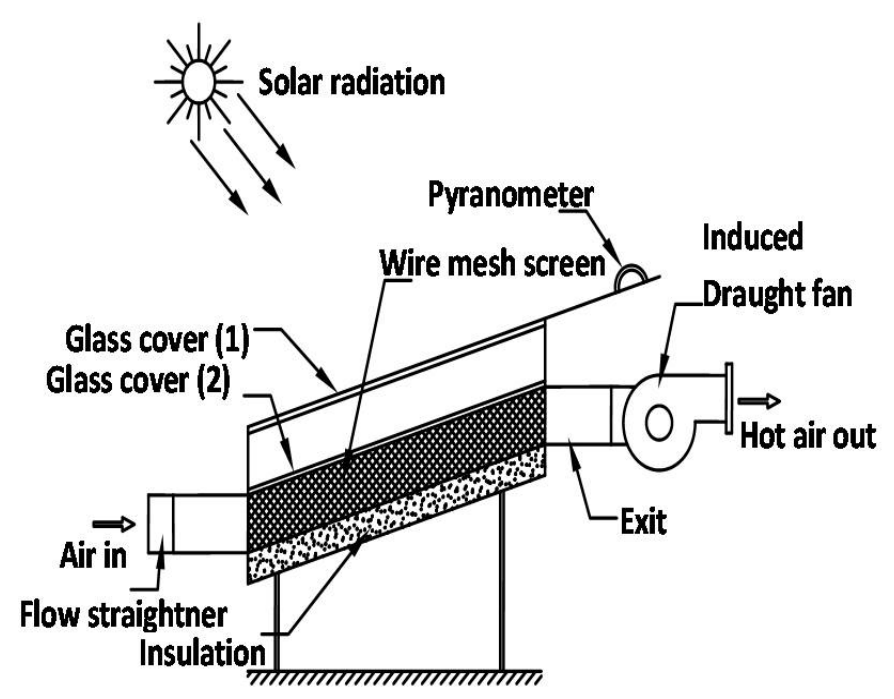

thick and sides of the collector duck are packed with thermocol insulation to minimize heat losses. An autotransformer is used to vary the speed of the blower. An anemometer is used to measure the velocity of the air. Calibrated copper-constantan thermocouples were used to measure the temperature of the air and the heated

Fig. 2. Cross sectional view of a wire mesh collector.

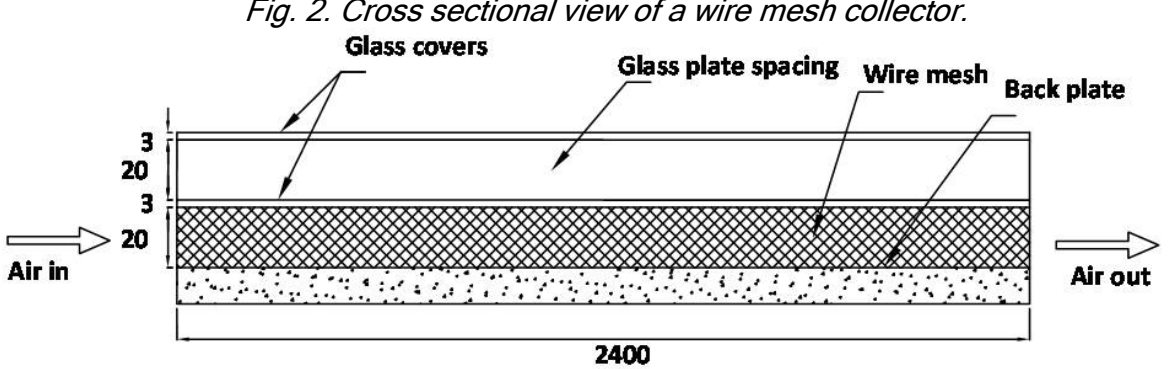

"Solar heater" http://www.indjst.org
Velmurugan \& Ramesh Indian J.Sci.Technol. 
Indian Journal of Science and Technology

Fig. 3. Absorber plate temperature of wire mesh \& conventional flat plate air heater.

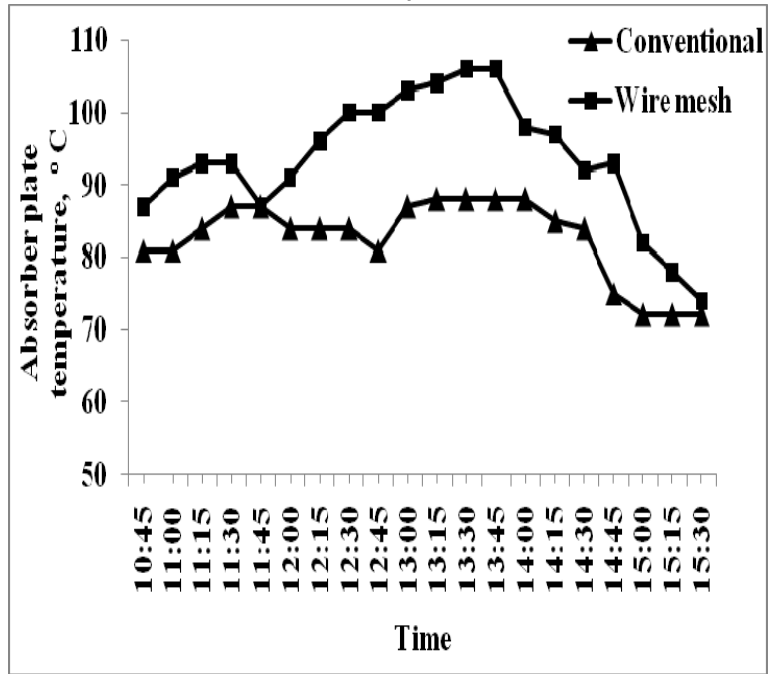

Fig. 5. Thermal efficiency of wire mesh \& conventional flat plate air heater.

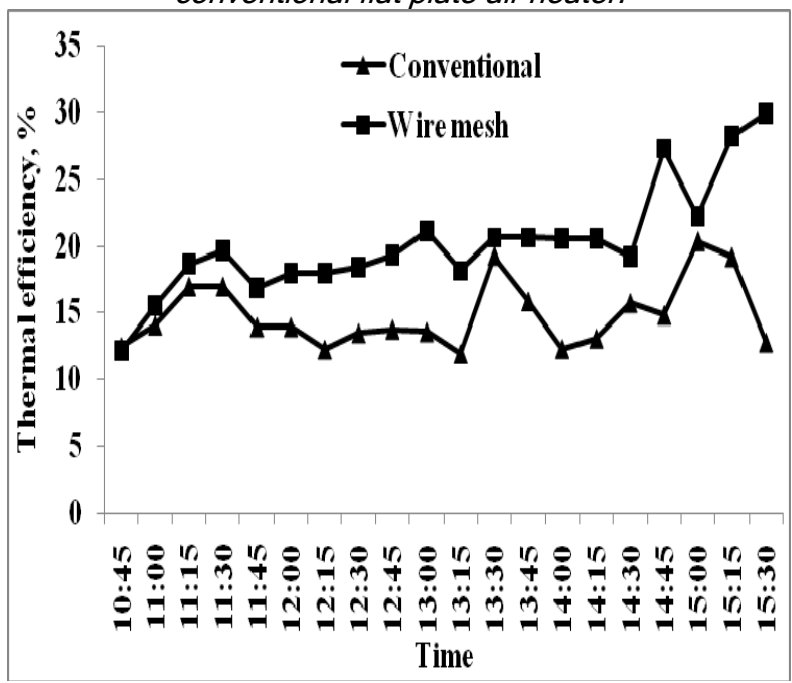

Vol. 4 No. 1 (Jan 2011)

ISSN: 0974- 6846

Fig. 4. Heat gain of wire mesh \& conventional flat plate air heater.

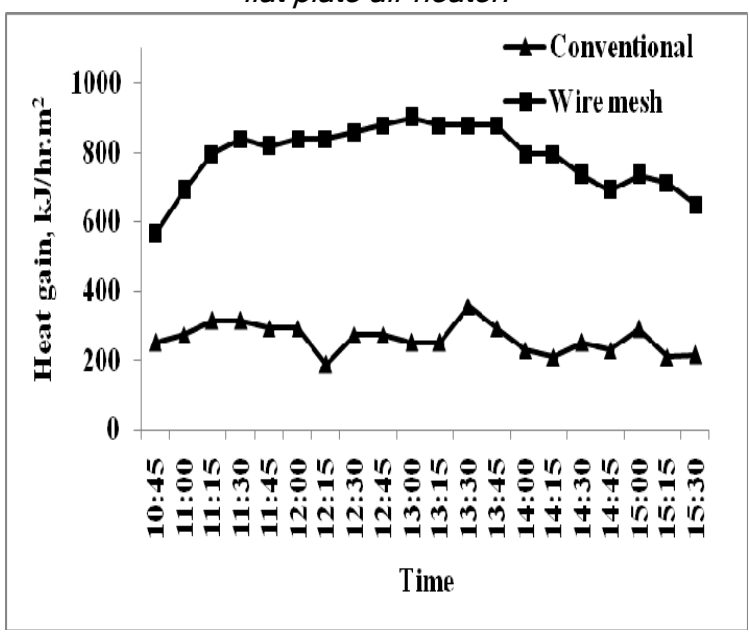

Fig. 6. Solar intensity at different mass flow rate of wire mesh air heater.

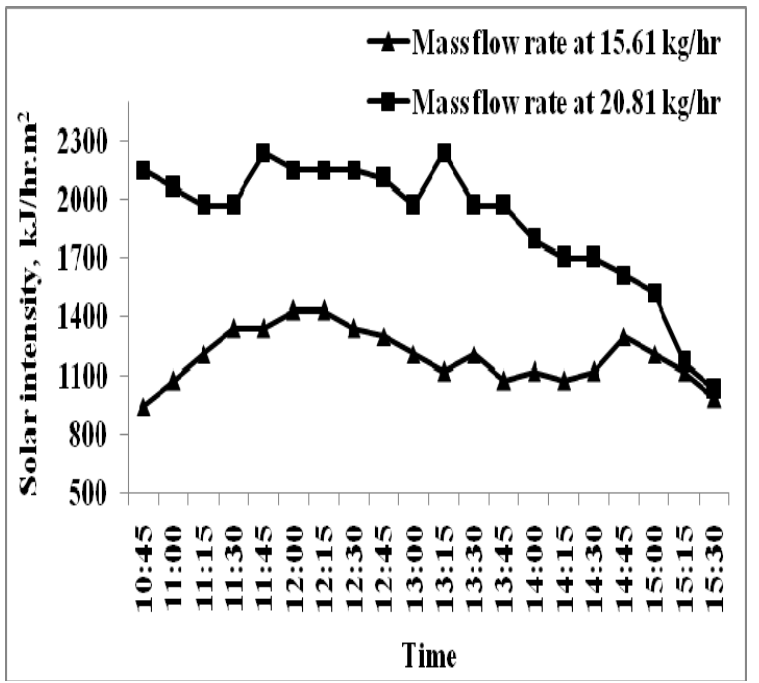

Fig. 7. Thermal efficiency at different mass flow rate of wire mesh air heater.

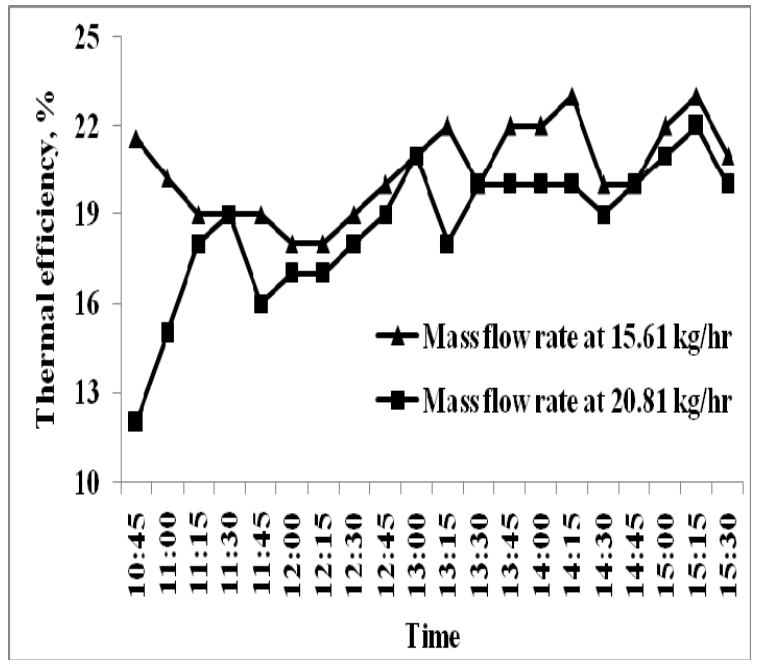


plate at different locations and were measured by a digital micro-voltmeter.

\section{Experimental procedure}

To start, all components were checked and instruments are calibrated. The blower is then switched "on" and joints have been checked for leakages. Experiments were conducted on 2 different conditions having different solar intensity. The mass flow rate was varied from $15.61 \mathrm{~kg} / \mathrm{h}$ to $20.81 \mathrm{~kg} / \mathrm{h}$. The following parameters were measured 1) Solar intensity, 2) Absorber plate temperature 3) Inlet air temperature 4) Outlet air temperature 5) Glass covers temperature 6) Air velocity.

\section{Results and discussion}

The useful heat gain $\left(Q_{u}\right)$ by the working fluid is given in the following equation (Sukhatme, 1993):

$Q_{u}=m C_{p}\left(T_{\text {out }}-T_{\text {in }}\right) \quad(1)$

Where, $T_{\text {in }}, T_{\text {out }}, C_{p}$ and $m$ are the fluid inlet, outlet temperature, heat capacity and mass of the fluid respectively.

Thermal efficiency of the solar collector is given by (Sukhatme, 1993):

$$
\eta_{\text {en }}=\frac{Q_{u}}{I_{T} A_{P}}
$$

Where, $I_{T}$ and $A_{P}$ are the incident solar energy per unit area of the absorber plate and area of the absorber plate, respectively.

Absorber plate temperature, solar intensity, heat gain and thermal efficiency are higher during the middle section of the experimental duration. From Fig. 3 it is observed that the absorber plate temperature with wire mesh is higher compared with conventional flat plate air collector when conditions are kept similar (Solar intensity $\&$ mass flow rate were constant). This may be due the placement of wire mesh in the modified system. The wire mesh may reduce the intensity of reflected radiation back to the glass cover and convective heat loss. It is also observed that temperature of the glass cover in the modified flat plate collector is less than the conventional flat plate collector because of minimum loss of heat; the absorber plate temperature is high compared to conventional system. The equations (1) \& (2) were used for calculating heat gain and efficiency. Fig. 4 \& 5 compares the heat gain and efficiency with respect to time, between the 2 types of flat plate collectors. It is observed that the efficiency and heat gain are higher with wire mesh type flat plate collector, compared with conventional collector. In the modified system the contact area is enhanced due to the provision of low carbon steel mesh, which increases the convective heat transfer. This will result in higher heat gain and thermal efficiency. Even though the traditional system receives the same solar intensity, there is apparently less area available to transfer the received heat into the air. Because of this, the heat gain by the air and efficiency are less compared to the modified system. Fig. $6 \& 7$ shows the comparison of solar intensity and thermal efficiency with respect to time. The experiments were conducted at two solar intensities.

When the mass flow rate is maintained at $15.61 \mathrm{~kg} / \mathrm{h}$ having a low solar intensity, the efficiency is more. When the solar intensity is more, the mass flow is increased from $15.61 \mathrm{~kg} / \mathrm{h}$ to $20.81 \mathrm{~kg} / \mathrm{h}$ the efficiency is reduced. Hence it can be concluded that the solar intensity has little or no influence on the collector efficiency, where as the mass flow rate influences the performance of solar air heater. From Fig. 3-7 it was absorbed that absorbed plate temperature, solar intensity, heat gain and thermal efficiency were higher during the middle region of the day.

\section{Conclusion}

By employing a low carbon steel wire mesh a $5 \%$ increase in overall efficiency is observed when compared with conventional system. Mass flow rate influences the thermal efficiency of the air heater. Solar intensity has no effect on thermal efficiency.

\section{References}

1. Choudhury C (1988) Solar air heater for low temperature applications. Solar Energy. 40(4), 35-344.

2. Collier RK and Arnold FH (1980) Comparison of transpired beds for solar collector applications. In: Proc. of the annual ISES meeting. pp:451-455.

3. Hachemi A (1995) Thermal performance enhancement of solar air heater by a fan-blown absorber plate with rectangular fins. Int. J. Energy Res. 19, 567-578.

4. Hollands KGT (1963) Direction selectively; emittance and absorption properties of three corrugated specular surfaces. Solar Energy. 7(3), 108-116.

5. Kalogirou SA (2004) Solar thermal collector and applications. Prog. Energy Combustion Sci. 30, 231295.

6. Lansing FL, Clarke V and Reynold R (1979) A high performance porous flat-plate solar collector. Energy. $4,685-694$.

7. Prasad K and Mullick SC (1983) Heat transfer characteristics of a solar air heater used for drying purposes. Appl. Energy.13, 83-93.

8. Rittidech S and Wannapakne S (2007) Experimental study of the performance of a solar collector by closed-end oscillating heat pipe. Appl.Thermal Engg. 27, 1978-1985.

9. Sorous MM and Hassab MA (1986) A screen type solar air heater. In: Proc. of the $8^{\text {th }}$ int. heat transfer conf. pp:3097- 3103.

10.Sukhatme SP (1993) Solar energy. McGraw-Hill, NY. pp:83-139.

11.Swartman RK and Ogunladeo (1966) An investigation on packed-bed collectors. Solar Energy. 10, 106-110.

12. Yeh HM and Lin TT (1996) Efficiency improvement of flat-plate solar air heater. Energy. 21(7), 435-443.
Research article

COIndian Society for Education and Environment (iSee)
"Solar heater"

http://www.indjst.org
Velmurugan \& Ramesh Indian J.Sci.Technol. 